\title{
Series spaces: Revisiting and re-evaluating Inspector Morse
}

Lucy Fife Donaldson, University of St Andrews

\begin{abstract}
Previous writing on the hugely popular series Inspector Morse (1987-1998) has stressed the presentation of space and place as conforming to a heritage aesthetic, characterized by quality and nostalgia. This article seeks to address how television drama can be re-evaluated through a methodology of longitudinal analysis, and the ways this process itself encourages sensitivity to how space is articulated. Inspector Morse offers a specifically televisual experience of space, involving repeated encounters with particular spaces by virtue of its long run. This is a spatial experience characterized by layering and accumulation of meaning, a textured or thickened contact with space. Drawing on the detail of pattern and embellishment arising from repeated contact with particular spaces, it explores the density of aesthetic choices which create images of spatial disjunction suitable to the generic context of Inspector Morse. In underlining that the programme's handling of space is more complex than previously suggested, this article seeks to demonstrate that the construction of space and place in Inspector Morse is not limited to the kind of 'heritage' qualities commonly associated with the programme.
\end{abstract}

\section{Keywords}

Inspector Morse 
space

aesthetics

place

detective series

texture

Watching a television series (or serial) involves the visiting and revisiting of spaces that make up a particular fictional world. Through the course of watching a number of episodes, we become familiar with the interiors and exteriors that characters inhabit, whether these are domestic or work environments, routes of travel or transition. This is a distinctively televisual experience of space. Where television space differs from that found in the cinema, is that the television series / serial offers repeated encounters during the course of a programme, which may span days, weeks, months and even years. Such an expansion of contact with a space entails that strategies of presentation aren't necessarily as bound to the need to immediately establish a location in order to orient a viewer, as they might be in a film. Rather, these can be revealed gradually over time, for the television viewer will be given the opportunity to revisit the world again and again, enabling an experience of space characterized by familiarity and detail.

Some programmes involve a large variety of spaces to encounter, while others are situated in more limited locations. Clearly this depends on a range of factors which might be historical (confinement to the studio due to demands of technology and institutional practice), economic (the size of the budget may determine number of locations / sets), or generic (the sitcom specializes in constricting the variation of spaces). As has been noted, the soap opera offers the most extreme case of this 
tendency, permitting viewers to revisit the homes or workplaces of characters several times a week, possibly over the course of decades (Lury 2005: 154). While perhaps not as intense, this kind of spatial experience is present in other forms of serialized drama, in both self-contained series narratives and the ongoing serial, where the revisiting of space might be due to the domestic or institutional demands of a narrative: the office in the workplace sitcom, the drawing room in the period drama, the police station in the detective series.

This article seeks to propose that television offers a specific experience of space and moreover that televisual space comprises layers, in that encounters with a particular kitchen or street corner are informed and built on by previous visits. Such particularities of spatial experience require a methodology that can capture the kind of layered spatial contact offered. In order to be able to recognize and apprehend echoes, the way space can be made familiar or strange through aesthetic consistencies and adjustments, a longitudinal approach is needed. Watching all of a series, as Billy Smart has argued (2012), enables understanding of the way it works as an overall composition. Not only does a longitudinal approach inform a detailed knowledge of narrative and character, but it also nurtures attentiveness to how space is treated, including the formation of patterns, embellishment and their interruption. This methodology is particularly well-suited to a concern with aesthetics, supporting attention to the textual detail of a programme, and how this contributes to meaning. Clearly the decision to watch an entire run of a series / serial represents a challenge, both in terms of the time-consuming effort of watching many hours of television, and the prospect of holding onto the specificity of spatial detail across a long-running programme. Yet, the reward for this kind of detailed approach goes beyond simply an in-depth knowledge of one particular television drama. As Smart notes, 
the process of watching all of Juliet Bravo (1980-1985) has taught me more than an acute understanding of Juliet Bravo itself. Through my rigorous methodology of watching all of it, I now have a much better understanding about the BBC, the form of television drama itself, even changing social attitudes towards the purpose and value of policing in the 1980s. (2012)

While my own analysis will be focused on the experience of space in a particular programme, seven series of detective series Inspector Morse (1987-1998), this article is further concerned with the ways television drama can be re-evaluated through a methodology of longitudinal analysis, and how this process itself encourages sensitivity to how space is articulated. If, as Sarah Cardwell suggests, views of scenery characterized by a long duration, slow pace and superfluity to narrative are markers of its 'cinematic' style (2002: 122), it is my intention to show that, on the contrary, Inspector Morse structures our experience of space in a specifically televisual way. A regular viewer of Inspector Morse quickly becomes familiar with the Oxford of the drama's setting, and with certain interiors: Inspector Morse's (John Thaw) home, his regular pub and spaces associated with his work, including corridors in the police station, the interview room, the office he shares with Sergeant Lewis (Kevin Whately) and Radcliffe Infirmary (its wards and pathology labs). By virtue of its long run, Inspector Morse offers a depth of experience, repeated encounters with particular spaces over the course of six years (and more if you include expansions of the fictional world provided by the specials and spin offs), from which emerge a layered, or textured, approach to space and place. 


\section{Returning to spaces}

Amy Holdsworth's work on nostalgia and memory in television considers moments of return, drawing attention to ways in which the television experience has been articulated as an 'ebb and flow' featuring currents of regularity, return, movement and stasis. While she explores moments of return (the idea of the 'moment' as both fleeting and momentous) that call attention to themselves as repetition more explicitly than the ones I will be investigating, Holdsworth's argument contains thoughts about the nature of television's seriality that intertwine with my own concerns with the layering involved in the return to space. Holdsworth conceives moments of return as a form of 'haunting', a term appropriate to her focus on nostalgia, and uses words like resonance, pattern, reflection, all of which conjure repetition as experience, perhaps emotional and physical. Being attentive to the particular rhythms of serial drama's narrative structure is to register pattern:

Central to [the relationship between television and memory] is the idea of the television viewing experience as one of accumulation, where viewing experiences and references are built up over time, and the memory of 'afterimages' and 'moments' is accumulated over a life lived across television. (2011: 34)

Holdsworth's investment in engaging with television as a material object leads to the conceptualization of a strongly textured medium, one created and perpetuated through a process of layering, where the fine detail of the narrative (the moment) contributes to the pattern of the overall fabric (the series / serial structure). 'Texture' has its basis in the process of weaving, involving the construction of fabric through intermeshing 
of materials chosen (the warp and weft), ${ }^{1}$ the decisions made in this process determining the feel and constitution of the cloth. In this sense it concerns the character or quality of something as resulting from its making or composition; an affective connection between detail and structure. Texture is at once the material consistency produced by aspects of mise-en-scène within a shot and rhythmic progression of editing from shot to shot. In music, texture has an explicitly structural basis as it 'concerns the number of musical strands or layers occurring simultaneously and the type and nature of the connections among them' (Buhler et al. 2010: 47). Bringing in these textural perspectives, the accumulation that Holdsworth centralizes in the viewing experience could be thought of as a layering of particular strands, resulting in a thickening of experience over time as a result of repetitions and the build up of references. While Holdsworth is making a larger point about the experience of television, this observation can also be applied to a particular text as well, as experiences accumulate over time through the course of a series.

Clearly the repetitions involved in television drama are multiple. Holdsworth focuses particularly on the shaping of narrative, which incorporates references made through audio-visual means, though at the beginning of her book she raises the issue of references beyond the text itself, the memories of watching in a particular time and place, for example. For consideration of how the depiction of space within the television drama might contribute to a series' texture, my analysis focuses partly on space as a backdrop for action - an environment where encounters and narrative events might take place. For this kind of space, repetition is a feature that can contribute to orientation in a location. Like most television, Inspector Morse features the same locations time and again in order to anchor the presence and character of its setting. At the same time, this consistency is not rooted in a desire to map out Oxford 
for the viewer, as the qualities of its spaces as presented are less about making realworld connections and more to do with communicating an overall composition of Oxford made up of a number of varied details. Landmarks have been chosen to represent aspects of city and communicate the nature of the place as well as certain types of spatial relations - not least because such views are often in the context of moving through space. Watching Inspector Morse entails a familiarity with the iconography of Oxford, but not necessarily a precise geographical understanding. The creation of familiarity spans a range of spatial markers of place, from what Lyn Thomas refers to as its 'awe-inspiring architecture' (1995: 8), like the stone-carved heads outside the Sheldonian - which constitute an introduction to Oxford proper in the first episode 'The Dead of Jericho' (1.1) and continue to crop up in shots of the city during the series (Figure 1) - to the mundane, such as the railway station, which marks the frequent comings and going of characters. Exterior locations are subject to repetition and return, due to the importance of Oxford as the drama's setting. ${ }^{2} \mathrm{We}$ might consider repetition as a key element of our topographical experiences, important for mapping out orientation to a particular place - repeated landmarks or particular views allow us to recognize Oxford - and through decisions made about exactly what to repeat, indicating how we might be invited to respond to it. It is on the exteriors I will focus, in order to consider the fabric of Oxford as a space - how the programme registers expectations and how its aesthetic strategies shape attitudes towards Oxford.

Figure 1: Sheldonian Heads as seen in 'Absolute Conviction' (6.4).

An often-repeated landmark in the series is Magdalen Bridge, which marries 
impulses of spectacle and everydayness as both a recognizable 'Oxford' location, associated with the college and its pastoral surroundings, and as a busy interchange integral to modern Oxford life. This duality is captured elegantly in the opening shot of 'Last Seen Wearing' (2.2), as the camera pans left from a long shot of the bridge flanked by foliage, the architectural detail of its arches and balustrade visible, and upwards as a red double-decker bus crosses it (Figures 2 and 3). The foreground of the shot is taken up with bright flowers and foliage covering a wrought iron fence, the bus with its contemporary advertising graphics in the middle and the bell tower of Magdalen College in the background. In this shot, the camera's positioning works to condense various facets of the space - its tradition, modernity, beauty and mundanity - into a single perspective. While the shot is involved in establishing location, it is also contributing to a wider sense of the constitution of Oxford, and thereby serves a descriptive purpose.

Figure 2: Magdalen Bridge in 'Last Seen Wearing'.

Figure 3: From below the bridge towards Magdalen College ('Last Seen Wearing').

The repetition of Magdalen Bridge also functions as a site of transition, providing passage from one place to another. In 'The Settling of the Sun' (2.3) Morse crosses the bridge with his friend Dr Robson (Anne Calder-Marshall) and her wheelchairbound father (Llewellyn Rees), and here the busy traffic passes in front of them, as the camera remains further back. 'Driven to Distraction' (4.3) concludes with Morse driving his distinctive Jaguar across the bridge, shot from behind as he approaches and then with a pan left so that the car drives away from the camera with the bell tower in the background (Figure 4). In this instance, there is less traffic and the bridge 
is devoid of buses, inflecting this as a more straightforwardly tourist view of a prominent landmark. Although both instances of crossing could seem to be operating outside of the narrative, for reasons of utility or even non-narrative spectacle, the differences are instructive to how they inform and contribute to mood. The first scene, with visual interruptions of traffic between camera and figures, operates as a busy prelude to the father's violent nightmare that occurs in the botanical gardens moments later. In contrast, the relative peacefulness of the concluding moments provides a fitting release after the thrilling revelation of the murderer and Morse's near death experience, all of which took place in another car.

Figure 4: The final shot in 'Driven to Distraction'.

The bridge is integrated in the narrative, becoming the dramatic setting for plot action in 'The Secret of Bay 5B' (3.4), where George Henderson (George Irving) destroys a tape sent by his wife's ex-lover. In this instance, although the bell tower is visible in the background, the architectural detail is downplayed by limited lighting the scene takes place at dusk - and closer framing. George is kept in the centre of the shot, the camera first panning with his movements as he gets out of his car and walks towards the balustrade, and then there is a second static low angle shot of George as he throws the tape forcefully off the side and then leans on the stone lintel, sinking his head onto his arms (Figures 5 and 6).

Figure 5: George seen from within his car in 'The Secret of Bay 5B'.

Figure 6: George throws the tape from Magdalen Bridge ('The Secret of Bay 5B'). 
Through these repeated encounters with Magdalen Bridge, we can start to comprehend a density in the spatial qualities of certain places. Through the layers of these examples, their patterns and embellishment are perceptible. For example, having seen much more of the space in the other occasions, the constrained view is much more striking in 'The Secret of Bay 5B'. And furthermore, we can recognize that the particular qualities of a place are captured by the kind of decisions around how to present it. The spatial features of Magdalen Bridge - it is fairly wide and features an impressive backdrop - seem to invite a panning movement across, in order to capture such an expanse of space. This invitation to pan could be tied to the heritage aesthetic, the 'languid panning shots of Oxford (where it is always summer)' which, for Richard Sparks, 'announces that this quality television' (1993: 90). ${ }^{3}$ However it is also clearly a response to the difficulty of capturing the bridge within one frame because of the flow of buses (and other traffic) that obscure figures and architectural details behind. The demands of the space in its aesthetic presentation therefore combine splendour and the everyday.

\section{Thickening experience}

While the example of repeated views of Magdalen Bridge might be more or less noticeable, there are other types of repeated space that register more prominently. The layered qualities of our experience of space in the drama is further shaped by the nature of the drama, and here issues of genre have a significant bearing on the spaces that become thickened through multiple encounters, and their particular characteristics, the specifics of which inform the broader shape or fabric of space in the series. The types of spaces we encounter are clearly tied to Inspector Morse's generic context and fit with expectations around that (police station, interview room), 
but they are also specific to the particular text; Morse thinks better in the pub than in the office, for instance, and there are spaces typical to the police series that we never or rarely see (incident rooms, evidence stores, communal offices). As mentioned earlier, familiarity and repetition is crucial to another television genre: the soap opera. For Karen Lury, this is tied specifically to a sense of place, noting that certain locations become a kind of magnetic field for the drama: '(the Rovers Return [Coronation Street], the Queen Vic, the Fowlers' living room [EastEnders]) are returned to again and again, over a period of years, and thus become extraordinarily familiar places to regular viewers' (2005: 154). The generic quality of this recurrence is also recognized by Amy Holdsworth: 'The rhythm of movement and stasis, the cyclicality and endlessness of the television text, emerges most clearly in writing on the soap opera (see, e.g., Geraghty 1981), and recurs again in recent work on “quality" serial television drama' (2011: 34). While these perspectives indicate that the soap opera might be a more obvious choice for considering the role of repetition in the experience of space on television, the detective series / police drama too offers rich opportunities for such discussion. Space is afforded particular importance within the genre by virtue of the crucial link between the work of the detective and space through examination of crime. Stijn Reijnders positions this link as bearing a relationship between detective and landscape formed through a dynamic of secrecy and revelation: 'For the TV detective, the landscape is a realm that contains certain secrets, which means that it needs to be passed through and investigated, in search of truth and justice' (2009: 173). Reijnders goes on to argue that the landscapes of detective series are imbued with guilt (drawing on the term 'guilty landscape' deriving from Dutch writer and artist Armando), rendering them as actively in tension with their apparent beauty or peacefulness (2009: 175). 
Over the progression of Inspector Morse's seven series, a body is discovered in / on a river or canal on four occasions. ${ }^{4}$ Of course, crime fiction is full of bodies discovered in water and it could be said that there is a practical logic to this, as the nature of the river is to both conceal and reveal. For the detective series, especially one where the identity of the killer is not privileged information known by the viewer, the river becomes a space of revelation, where things (bodies) are washed up and uncovered. All four instances are dramatic incidents, disrupting otherwise peaceful or pleasant events: tour guide Theodore Kemp (Simon Callow) floats past a couple enjoying an evening picnic by the river Chartwell in 'The Wolvercote Tongue' (2.1); holidaymakers on a narrowboat discover the remains of an academic floating in the canal at Thrupp in 'The Last Enemy' (3.2); two night-time fisherman hook a dead woman instead of a fish in 'Greeks Bearing Gifts' (5.4); and a dogwalker comes across the corpse of the journalist Neville Grimshaw lying in a punt in 'Twilight of the Gods' (7.3). These are also key plot events, and within each episode itself there are returns to the riverbank for Morse and Lewis to examine the scene, and in the first two episodes, on further occasions to walk along or stand by the river to discuss the case. Scrutiny of crime scenes, especially in the case of murder, entails careful consideration of the design details that make up particular spaces, both to support discovery of clues and to indicate a range of information that feeds into the work of profiling. Decisions about how to present this detail, how to frame a particular space, whether to cut in to close-up or show the detective in the act of finding clues, have an important role to play in our involvement in the investigation (whether we know more / the same / less than the detective, for example). This latter point also indicates a key aesthetic difference between generic investments in space. While the spaces of British soap opera are associated with a social realist aesthetic, a significant aspect of their 
presentation being their everyday familiarity, the detective series incorporates a range of aesthetics. Following Jonathan Bignell's examination of the 'aesthetic instability' of the police drama ([2009] 2014: 8), attention to the aesthetic complexities of space forms a central element of my focus on these larger moments of repetition in Inspector Morse.

In 'The Wolvercote Tongue', Theodore Kemp is killed by Cedric Downes (Kenneth Cranham), in revenge for Theo's affair with his wife, though at the time of his death it appears to be related to the first death of the episode - an American tourist - and a missing Anglo-Saxon treasure. In this instance the body in the river is presented with a certain amount of flourish. The camera moves quickly from behind the car the couple is sitting in front of, to a long shot of river. Although there seems to be nothing there, the couple - now in the foreground - are placed out of focus while the background of river, reeds and unidentified object is in focus (Figure 7). The moment of revelation begins with a clear view of a naked male body floating downstream face down, followed by another visual flourish of a more unsettling kind. As it hits a different flow of water, the body is caught, whereupon there is a cut to a close-up of the face of the woman on the riverbank as she looks off-screen and her eyes widen (Figure 8). At this point, there is a further cut to a long shot of the couple on the bank followed by a dolly zoom while both figures stare ahead, mouths open and eyes wide. Another cut takes us to a close-up of the body as it flops over to reveal the face, while off-screen the woman screams. Here, the dolly zoom, a startling effect in any situation, dramatically shifts spatial coordinates as the camera simultaneously zooms in and tracks out. Furthermore, the two instances of camera movement involved in this discovery of the body operate across a different axis to that of the flow of the river, imbuing the gesture with further harshness. The use of camera 
movement thereby coordinates bodies in the space - those of the dead man and the couple - in an unsettling manner, creating a rhythmic contrast to the peaceful qualities of the river (surely the reason the couple are there to enjoy a late night drink) and an almost abrasive charge to the revelation of the body in the forceful movement across the river's flow.

Figure 7: The couple doesn't notice the body at first ('The Wolvercote Tongue').

Figure 8: The woman sees the body ('The Wolvercote Tongue').

Building on camera movement as a way to create abrasive interruptions to spatial stability, 'The Last Enemy' utilizes axes shifts to inflect the discovery of the body. The episode opens with a zoom out from a man fishing by the side of a canal. A couple navigate their narrowboat past some moored boats, but due to a mishap with a bowl of cereal they veer off course into some reeds, where they find a headless body. The sequence is characterized by a largely leisurely pace, the scene beginning gently with soft non-diegetic music and a series of shots, which set up the tranquillity of the setting on the one hand - long shots of the boat on the canal with green countryside and other boats visible, a tracking shot from the bank which mirrors the gentle pace of the boat (Figures 9 and 10) - and the couple's unfamiliarity with operating a boat. The latter is established via a shot reverse-shot pattern that presents the man at one end of the boat in charge of the steering, though concentrating more on his cereal, and the woman sitting leisurely on the front end (Figures 11 and 12). To begin with they smile at one another across the length of the boat, but as it heads towards the bank she 
shouts instructions at him and then attempts to use a pole to prevent collision. The revelation of the body comes at the end of this sequence, and much like 'The Wolvercote Tongue' it is the woman (Susannah Hitching) who registers the discovery, and the pattern of a cut from her reaction to the body is repeated, with slight embellishment. From a medium shot of her as she bends over to poke about in the water, there is a cut to a long shot from the bank, the detail of action obscured through trees (Figures 13 and 14). After a moment there is a further close-up on her face as her expression changes and she screams (Figure 15), and then a cut to her point of view of the body in the water. This time the discovery of the body isn't presented quite as dramatically, but the disruption enacted on the space still articulates a degree of harshness. First, the change to her posture takes us into a different dramatic axis, her body directed sharply down, corresponding in some degree to the unsettling of space enacted by the dolly zoom. Second, the shot from the bank delays the moment of revelation, disrupting the rhythm of the sequence. In repeating a view previously presented as part of a gentle riverbank experience bringing together the pace of the boat and the camera alongside, there is the possibility of it working to retrospectively inflect and reconstitute the idyll of before.

Figure 9: Long shot emphasizing the tranquillity of the setting ('The Last Enemy').

Figure 10: The boat seen from the bank (The Last Enemy'). 
Figure 11: The man steering, but paying more attention to his cereal ('The Last Enemy').

Figure 12: The woman sitting on the front end of the boat ('The Last Enemy').

Figure 13: Low angle of the woman poking in the reeds ('The Last Enemy').

Figure 14: Long shot from the bank as the woman pokes in the reeds ('The Last Enemy').

Figure 15: The woman sees the body ('The Last Enemy').

Rhythmic interruption and delay is used to further unsettle experiences of space in 'The Twilight of the Gods', where the discovery of the body follows a series of scenes setting up the episode's principal characters and motivations. A credit sequence that brings the different narrative threads together is followed by a view of Oxford from a distance, with an expanse of green fields and trees in front (Figure 16). As with the previous examples, the dramatic and stylistic progression is from a peaceful pastoral scene to another version of the patterning of a woman's reaction and revelation of a dead body. A woman walks her dog along the river, presented in a long shot that shows green landscape behind her and the river to her left, and then another long shot from the other side of the bank, the camera panning with her movement until the punt by the river's edge is visible (Figures 17 and 18). Still situated on the opposite bank, the long shot remains as the woman notices something 
and the dog barks. A cut comes as she moves closer and the camera moves up the length of the body in the boat. A further cut, just as the camera reaches the head, takes us back to the woman as she walks closer and then stops, and there is cut in to a closeup of her, followed by a close-up of the dead man's head before a return to the woman as she clamps her hand over her mouth, pauses and then looks up and offscreen (Figure 19). A marked alteration to the pattern of reaction / revelation is found in the decision to replace the scream with a hand over her mouth. In keeping with this aural restraint, visually this is the least abrasive sequence. Yet, the scene retains a stylistic flourish in the tracking shot up the body, which echoes the unsettling of space seen in the sequences above through the shaky quality of the camera's movement. The literal spatial instability is then furthered by a disconnect between what had seemed to be a representation of the woman's point of view, and the shot that follows as the woman continues to move forwards and then reacts to the body. That the revelation is placed after a series of events with apparently no connection to this one, makes the unsteadiness apparent at a narrative level, so that the aesthetic decisions about how space is presented cohere with and contribute to the overall composition or texture of the episode.

Figure 16: View of Oxford ('Twilight of the Gods').

Figure 17: The woman walks her dog ('Twilight of the Gods').

Figure 18: View from the bank ('Twilight of the Gods'). 
Figure 19: The woman sees the body ('Twilight of the Gods').

What materializes from consideration of these moments is a pattern in the spatial presentation of the body found in a river based around a basic formula: a woman looking and reacting, followed by a cut to the dead body. There is also a rhythmic progression from languid or gentle to sharp or abrasive, through increasing cuts and movement into or across space. Within these repeated formulations, there are slight adjustments which create an embellishment in the pattern, shaped through a different manner of camera movement or progression of edits. As a result, it seems that this type of space invites certain kinds of views, dictated by the practicalities of shooting by a river or canal, the dramatic requirements of the moment and a desire to utilize the qualities of the water. I haven't included the discovery of a body in 'Greeks Bearing Gifts' largely because it is a much more compact sequence, but it too offers further adjustment to the pattern, through a gender reversal (men finding a woman) and adoption of a more static camera. All three sequences I've discussed feature considerable camera movement, which is not, as with Magdalen Bridge, an attempt to capture an expanse of space, but rather a response to the movement of the river and objects in / on it. For Katherine Shonfield, whose writing examines questions of design, architecture and film, the river emerges as centre and network - a site of connections and convergence - as well as unfixed and uncontainable. Although these bodies aren't all found in the same geographical place, and involve three separate bodies of water, the prominence of the association between murder and river / canal creates a building of meaning tied to a particular kind or type of space. Spatial qualities are further drawn out by the kind of aesthetic decisions made concerning the presentation of the river in relation to the drama of the moment. The way the camera 
moves and decisions about framing and blocking, as well as editing, render the experience of space in particular ways. The river (or canal) for Inspector Morse is certainly a site of connection, bringing the dead body to attention and through it creating links that form or are part of the narrative. At the same time, instability plays out in the oscillation between concealment and revelation, and through the unsettling of space.

The reworking of a pattern through the duration of the series creates a layered experience, so that the very appearance of the river comes to invite the idea of murder, becoming a warning sign to the experienced viewer. ${ }^{5}$ Evoking Richard Dyer's work on seriality through serial killer films, Holdsworth links expectation / anticipation and pattern: "pattern and the anticipation of repetition become part of the pleasures of seriality' (2011: 55). Such a connection casts additional meaning to the slight delays in the pattern of revelation / response. Placing anticipation in relation to repetition invests the cut to the view of the woman from the bank in 'The Last Enemy' with a degree of knowingness - the episode self-reflexively delays the finding of the body we already know is there. Likewise in 'The Twilight of the Gods' the delay between the tracking shot up the body and the point of view shot of the man's face, suggests a markedly deliberate attempt to prolong the moment. The very fact that the final episode in series seven initiates the narrative of detection with a dead body by the river further suggests self-reflexivity. Holdsworth identifies endings and beginnings as 'privileged spaces for reflection and remembering, where patterns are initiated and revealed' (2011:36), and while this episode doesn't initiate or reveal the pattern, it indicates a knowledge of the pleasures of anticipation and repetition by using a motif that we might associate with Inspector Morse. 


\section{Negotiating a heritage space}

When Morse is informed of the body in 'The Twilight of the Gods' his response directly addresses the event as a motif observable within the diegesis itself: 'It would be nice to enjoy the Isis [River Thames] now and then, instead of always having to drag bodies out of it'. If repetition seems to generate a self-reflexive impulse in a pattern of moments, it further typifies the series' approach to space, and therefore its sense of place. As Lury argues, places are given form through space: 'Places are constructed within audio-visual media (such as television and film) just as they are in the real world, that is, via spatial (and temporal) relationships' (2005: 149). In Inspector Morse, the presentation of spaces we encounter is held together by an exterior consistency: familiarity with Oxford spaces, both typical and not, is clearly a key aspect of the pleasures offered by the programme. Its depiction of place has been a central point in accounts of the programme, the focal point of a set of wider claims about what kind of series it is. Coming to a re-evaluation of Inspector Morse through the detail and density of its spaces presents an opportunity to address and renegotiate the interpretation of it as a prime example of conservative heritage drama.

Along with Richard Sparks and Lyn Thomas, Charlotte Brunsdon characterizes the series' treatment of Oxford as articulating nostalgic Englishness: 'that most characteristic Morse shot, the spectacular, narratively unnecessary crane or helicopter shot over Oxford, showing colleges, spires, greens - a visual present of a fantasy past' (1998: 231). For Thomas, the fantasy past is also supported through markers of setting and characteristics of space: 'This visual expression of Englishness requires village greens and gardens, medieval lanes and churches, and wood-panelled interiors where log fires burn even in high summer' (1995: 3). Clearly issues of 'quality' and 'Englishness' are intertwined here, the latter associated with the heritage export which 
is defined by Brunsdon as one of the principal components of 'quality' (1990: 86), a connection which is also central to Thomas' definition of the programme's mainstream status.

The relationship of Inspector Morse to its depiction of Oxford as characterized by these writers therefore connects to debates around heritage drama in British film and television. A key perspective on this is offered by Andrew Higson who conceptualizes the genre as being predicated on a bourgeois class perspective and an aesthetizing view of an English past: 'one of the central pleasures of the heritage film is the artful and spectacular projection of an elite, conservative vision of the national past' (1996a: 233). Such apparent conservatism - for all these writers Oxford is aligned with tradition, higher social classes, a rural or at least a non-metropolitan world - is further supported by the kind of certainty offered by claims around the programme's homogeneity. The continuing consumption of Morse's Oxford as a tourist attraction the proliferation of guides and tours feeding into Sparks' suggestion that the series operates almost as a travelogue - substantially backs up such connections between popularity, heritage, quality and aesthetics. Along these lines, accounts of the series are remarkably consistent, and in many ways it is entirely appropriate to see Inspector Morse and its enduring legacy as a useful example of British 'quality' drama, of heritage export television, and as Brunsdon does, as one of a number of British detective series that reject the 'gritty' police drama concerned with the dangers of modern policing and associated sexual politics (e.g., Prime Suspect [1991-2006] and The Cops [1998-2001]) for the 'cosy' distance from contemporary life offered by rural / small town surroundings (such as Midsomer Murders [1997-] and Pie in the Sky [1993-1997]) or a more elegant past (Agatha Christie's Poirot [1989-2013] and Miss Marple [1984-1992]). Robin Nelson ties this remove to a middle-class response 
to Thatcherism, grouping Inspector Morse with other television from the 1990s (his examples include: Heartbeat [1992-2010], The House of Elliot [1991-1994] and Middlemarch [1994]) that he suggests sustain a 'cultural reassurance' that 'resides in idealized British period settings' (1997: 176).

Yet, however valuable these arguments might be, I would like to suggest that they offer a useful starting point only, and that to take such a view is to merely scratch the surface of the attitudes to place and space found in Inspector Morse. My account of the series has sought to extend Helen Davis' efforts to break into the discourses of heritage and quality described above. For Davis 'describing Inspector Morse as "heritage TV" obscures some of the program's most significant modes of engagement with contemporary social issues' (2001: 135). While Davis' re-evaluation examines the programme's relationship to modern policing, mine seeks to challenge the aesthetic assumptions being made through discourses of heritage and spectacle. What attention to space has revealed is the extent to which Inspector Morse is interested in articulating various types of space within Oxford, which are in no way limited to an emphasis on architectural beauty or empty spectacle. Oxford as a place constituted by many different spaces makes it akin to a fabric - decisions about what to include in its construction affect the quality of the overall composition. While critical accounts have stressed the consistency of the series' strategies of presenting space (see Reijnders 2009; Thomas 1995), as the returns to Magdalen Bridge show, the Oxford of Inspector Morse is deliberately configured as multifaceted, combining antiquity and modernity, tranquility and bustle. The repetitions and embellishments in the body by the river discovery have served as a counterpoint to characterization of the series' visual style as languid. Rather, the detail of these three moments reveals abrasion and 
interrupted rhythms that cement instability, not artful heritage certainty, into our experience of space.

By virtue of its stable setting, the series is able to deliberately play with its attitudes to place, fulfilling and subverting the qualities of such views and even rejecting them altogether. What my analysis of the moments by the water or on Madgalen Bridge has sought to demonstrate is that Inspector Morse uses repetition and embellishment to scrutinize, explore and test the qualities of its location. Throughout the course of the series the kind of 'heritage' view described by Brunsdon, Thomas, Sparks and Reijnders are complicated and destabilized, so that the tensions between spectacle and narrative inscribed on views of landscape (Higson 1996b) are tangled, rendering the 'spectacle' of Oxford rather a series of accumulated images contributing to a larger, layered composition than a straightforward heritage space. 'The Infernal Serpent' (4.1) begins in an Oxford college, but on a rainy night. In 'Driven to Distraction' a transition between scenes is made via a long pan across Oxford's spires that then rejects empty spectacle in favour of locating Morse's car in relation to the city. A stately home is positioned as a key location in 'Cherubim and Seraphim' (6.5), only to be revealed not as the site of a body in the drawing room but that of a rave. The grandness of an Oxford landmark featured in 'The Wolvercote Tongue' is juxtaposed with views of its cramped hallways and windows obscured by scaffolding (Figures 20 and 21). As these few examples begin to demonstrate, the heritage view is frequently acknowledged and immediately undercut. There is a clear playfulness expressed through the presentation of space, as in 'Happy Families' (6.2), an episode which revolves around a rich family in a large country estate: the opening shot is a close-up of a toilet bowl. The certainty and mastery of space implied by critical claims of the series' consistency is undermined by its ability to simultaneously 
meet and subvert expectation.

Figure 20: The cramped hallway of The Randolph Hotel ('The Wolvercote Tongue').

Figure 21: Scaffolding mars the view from The Randolph Hotel ('The Wolvercote Tongue').

Although Sparks suggests that 'Morse himself embodies a deep ambivalence towards Oxford', he typifies aesthetic strategies as solely foregrounding pleasure: 'In the first place the camera dwells on Oxford with lingering pleasure. It enjoys its honey sandstone walls and gateways, college lawns, golden youth playing croquet, jumbled roofscape and so forth' (1993: 97). Far from lingering enjoyment, the strategies of how to present space explored through the course of this article have been revealed as interested in density and juxtaposition, instability and friction. The benefit of taking a longitudinal approach is that access to the variety of ways space is presented, and especially those spaces that are revisited, is revealed over the course of the series.

\section{Conclusion}

Due to its age it could be easy to dismiss a series like Inspector Morse as lacking complexity or aesthetic interest, especially when comparing it to the current 'golden era' of 'quality' and 'complex' television drama. The series' legacy endures through its two spin-off series - Lewis (2006-2014), following Lewis in his new role as Detective Inspector several years after Morse's death, and Endeavour (2012-), the 
prequel focusing on Morse as a young Detective Constable in the mid-1960s - both of which might be seen to further perpetuate the formulaic and conservative depiction of Oxford, feeding the continuation of the series' cultural capital as focused on its location. However, in underlining that the programme's handling of space is more complex than previously suggested, this article demonstrates that the construction of space and place in Inspector Morse is not limited to the kind of 'heritage' qualities commonly associated with the programme. The result of an in-depth investigation of space is recognition of the dense and layered articulations of space in Inspector Morse that limit nostalgia and seek to present the past in relation to the present. Space is not simply decorative spectacle, but describes the shape of Oxford over time. If we see Inspector Morse's Oxford as a fabric or overall composition, woven of different elements, it supports varied readings of the programme, both past - Thomas' feminist reading (1995) - and future. Attending to the particularities of a space and its construction therefore provides productive ways into describing the impact of television locations more generally, and this article contributes to developments in the discussion of spaces and television led by the AHRC-funded project 'Spaces of Television: Production, Site and Style' at the University of Reading. ${ }^{6}$ Focusing on how Oxford is presented links to writing which considers the uses of location in drama (e.g. Redmond 2014; Roach 2014; Smart 2014), while textual analysis refutes the alleged languid qualities of space through consideration of spatial disjunction, connecting to the role space plays in issues of and around genre (Lamb 2014; Piper 2014).

While close textual analysis of Inspector Morse has formed the substance of the article, re-evaluating a particular text in regards to how its approach to space and place has been characterized in the past, the methodological impulse offered aims to 
have a wider reach. Through exploration of repetition, my argument has circulated around the experience of space in Inspector Morse as inherently televisual. The very fact that we return to the same interiors and exteriors week after week, year after year, marks out a spatial contact unavailable in cinema. The programme can thus be seen to be engaging in a longer dialogue with space and its varied possibilities, how this shapes attitudes to place, and how these in turn can be subverted. The attentiveness to space enabled through a longitudinal approach uncovers a variety of ways it can function and contribute to the texture of a series. Aesthetic attention to the return to space is therefore an effort to value the specific experience of television drama, as well as the achievements of visual style.

\section{Acknowledgements}

This article is one of the outcomes of the research project 'Spaces of Television: Production, Site and Style', funded by the Arts and Humanities Research Council (grant number AH/H018662) from 2010 to 2015 and based at the University of Reading. I am grateful to Jonathan Bignell and Leah Panos for their insightful comments and suggestions during the writing process. I would also like to extend my thanks to the anonymous readers, and to Tom Rice, for their thoughtful encouragement of the article and constructive suggestions for revisions.

\section{References}

Bignell, J. ([2009] 2014), 'The Police Series (e-book)', Movie: A Journal of Film Criticism, http://www2.warwick.ac.uk/fac/arts/film/movie/ebooks/. Accessed 24 June 2014. 
Brunsdon, C. (1990), 'Problems with quality', Screen, 31:1, pp. 67-90. (1998), 'Structure of anxiety: Recent television crime fiction', Screen, 39:3, pp. $223-43$.

Buhler, J., Neumeyer, D. and Deemer, R. (2010), Hearing the Movies: Music and Sound in Film History, New York/Oxford: Oxford University Press.

Bullen, A. (2010), Morse in Oxford, Stroud, Gloucestershire: The History Press.

Cardwell, S. (2002), Adaptation Revisited: Television and the Classic Novel, Manchester: Manchester University Press.

Davis, H. (2001), 'Inspector Morse and the business of crime', Television and New Media, 2:2, pp. 133-48.

Donaldson, L. F. (2014), Texture in Film, Basingstoke: Palgrave Macmillan.

Geraghty, C. (1981), ‘The continuous serial - a definition’, in R. Dyer (ed.), Coronation Street, London: BFI, pp. 9-26.

Goodwin, C. (2002), Inspector Morse Country: An Illustrated Guide to the World of Oxford's Famous Detective, London: Headline Books.

Higson, A. (1996a), 'The heritage film and British cinema', in A. Higson (ed.), 
Dissolving Views: Key Writings on British Cinema, London: Cassell, pp. 232-49. (1996b), 'Space, place, spectacle: Landscape and townscape in the "Kitchen Sink" Film', in A. Higson (ed.), Dissolving Views: Key Writings on British Cinema, London: Cassell, pp. 133-56.

Holdsworth, A. (2011), Television, Memory and Nostalgia, Basingstoke: Palgrave Macmillan.

Lamb, B. (2014), 'Ah! Our very own Juliet Bravo, or is it Jill Gascoine? Ashes to Ashes and representations of gender', in J. Bignell and S. Lacey (eds), British Television Drama: Past, Present and Future, 2nd ed., Basingstoke: Palgrave Macmillan, pp. 203-13.

Leonard, B. (2008), The Oxford of Inspector Morse and Lewis, Gloucestershire: Tempus.

Lury, K. (2005), Interpreting Television, London: Hodder Education.

Nelson, R. (1997), TV Drama in Transition: Forms, Values and Cultural Change, Basingstoke: Macmillan.

Piper, H. (2014), 'Estates and lock-ups: Generic space and place in early 1990s TV crime', Film and Television Research Seminar Series, University of Bristol, Bristol, 26 March. 
Redmond, P. (2014), 'Brookside: The technology backstory', in J. Bignell and S. Lacey (eds), British Television Drama: Past, Present and Future, 2nd ed., Basingstoke: Palgrave Macmillan, pp. 62-69.

Reijnders, S. (2009), 'Watching the detectives: Inside the guilty landscapes of Inspector Morse, Baantjer and Wallander', European Journal of Communication, $24: 2$, pp. $165-81$.

(2010), 'Places of the imagination: An ethnography of the TV detective tour', Cultural Geographies, 17:1, pp. 37-52.

Richards, A. (2011), Inspector Morse on Location: The Companion to the Original and Bestselling Guide to The Oxford of Inspector Morse, Sawston, Cambridge: Irregular Special Press.

Richards, A. and Atwell, P. (2012), The Oxford of Inspector Morse, 12th rev. ed., Sawston, Cambridge: Irregular Special Press.

Roach, C. (2014), 'Moving Waterloo Road from Rochdale to Greenock: Exploring a sense of place in drama series', in J. Bignell and S. Lacey (eds), British Television Drama: Past, Present and Future, 2nd ed., Basingstoke: Palgrave Macmillan, pp. 184-90.

Smart, B. (2012), 'The case of Juliet Bravo: You have to watch all of a series to truly 
understand a series', CSTOnline, http://cstonline.tv/juliet-bravo. Accessed 1 July 2014.

(2014), 'Plot Inflation in Greater Weatherfield: Coronation Street in the 1990s',

in J. Bignell and S. Lacey (eds), British Television Drama: Past, Present and Future, 2nd ed., Basingstoke: Palgrave Macmillan, pp. 70-83.

Shonfield, K. (2000), Walls Have Feelings: Architecture, Film and the City, London and New York: Routledge.

Sparks, R. (1993), 'Inspector Morse: “The Last Enemy” (Peter Buckman)', in G. W. Brandt (ed.), British Television Drama in the 1980s, Cambridge: Cambridge University Press, pp. 86-102.

Thomas, L. (1995), 'In love with Inspector Morse: Feminist subculture and quality television', Feminist Review, 51, pp. 1-25.

\section{Television programmes}

Agatha Christie's Poirot (1989-2013, UK: ITV).

The Cops (1998-2001, UK: BBC).

Endeavour (2012-, UK: ITV).

Heartbeat (1992-2010, UK: ITV).

The House of Elliot (1991-1994, UK: BBC).

Inspector Morse (1987-1998, UK: ITV).

'The Dead of Jericho' (Series 1, Episode 1, 6 January 1987). 
‘The Wolvercote Tongue' (Series 2, Episode 1, 25 December 1987).

'Last Seen Wearing' (Series 2, Episode 2, 8 March 1988).

'The Settling of the Sun' (Series 2, Episode 3, 15 March 1988).

‘The Last Enemy’ (Series 3, Episode 2, 11 January 1989).

'The Secret of Bay 5B' (Series 3, Episode 4, 25 January 1989).

'The Infernal Serpent' (Series 4, Episode 1, 3 January 1990).

'Driven to Distraction' (Series 4, Episode 3, 17 January 1990).

‘Greeks Bearing Gifts' (Series 5, Episode 4, 20 March 1991).

‘Happy Families' (Series 6, Episode 2, 11 March 1992).

‘Absolute Conviction' (Series 6, Episode 4, 8 April 1992).

'Cherubim and Seraphim' (Series 6, Episode 5, 15 April 1992).

'Twilight of the Gods' (Series 7, Episode 3, 20 January 1993).

Juliet Bravo (1980-1985, UK: BBC).

Lewis (2006-2014, UK: ITV).

Middlemarch (1994, UK: BBC).

Midsomer Murders (1997-, UK: ITV).

Miss Marple (1984-1992, UK: BBC).

Pie in the Sky (1993-1997, UK: BBC).

Prime Suspect (1991-2006, UK: ITV).

\section{Contributor details}

Lucy Fife Donaldson is a Lecturer at the University of St Andrews. This article was written while she was Post-Doctoral researcher on the AHRC-funded project 'Spaces 
of Television, Site and Style' at the University of Reading. Her research focuses on the materiality of style and the body in popular film and television and she is a member of the Editorial Board of Movie: A Journal of Film Criticism.

Contact:

Film Studies, University of St Andrews, 101A North Street, St Andrews, Fife, KY16 9AD, UK.

E-mail:1fd2@st-andrews.ac.uk

Notes

${ }^{1}$ For a detailed discussion of how interdisciplinary approaches to texture can inform articulation of it elsewhere see Donaldson (2014: 14-48).

${ }^{2}$ My analysis has been supported by the large amount of extratextual material produced concerning Inspector Morse's location (see Goodwin 2002; Leonard 2008; Bullen 2010; Richards 2011; Richards and Atwell 2012).

${ }^{3}$ Other markers of 'quality', drawing on Charlotte Brunsdon's definition (1990), that Inspector Morse fulfills are: adaptation from a literary source; 'the best of British acting' - an array of guest stars such as John Gielgud, Harriet Walters and Diana Quick; money, as indicated by decisions to shoot on film and on location.

${ }^{4}$ The motif is continued beyond the seven series in the special episodes where a body is discovered in a punt ('The Daughters of Cain' [1995]) and investigation of historical murders based around the Oxford canals ('The Wench is Dead' [1998]). ${ }^{5}$ The association of water and murder spreads out further, with murders taking place near the canal in 'The Dead of Jericho' (1.1), a murder victim seen (but not discovered) in a boat some distance from Oxford in 'The Service of All the Dead' 
(1.3), the identity of the murderer revealed outside a boathouse during boat races in 'The Secret of Bay 5B' (3.4), and evidence hidden inside a boathouse in 'Deadly Slumber' (7.1). The river is used to conceal, as when George Henderson throws a tape into the river, an action repeated in 'Dead on Time' (6.1) by Lewis who throws a tape in the river Cherwell to protect Morse.

${ }^{6}$ More information on the project is available online:

http://www.reading.ac.uk/ftt/research/Spacesoftelevision.aspx. 